\title{
MOVIMENTO DE MULHERES E FEMINISTAS E SUA AÇÃO ANTICAPITALISTA NO BRASIL E MARANHÃO
}

\author{
Mary Ferreira \\ Universidade Federal do Maranhão (UFMA)
}

MOVIMENTO DE MULHERES E FEMINISTAS E SUA AÇÃO ANTICAPITALISTA NO BRASIL E MARANHÃO

Resumo: A ação do feminismo no Brasil tem como marco os anos setenta, quando este movimento irradia para vários estados brasileiros, trazendo para a sociedade a perspectiva das mulheres na construção de uma sociedade sem relações de gênero, em que pudessem partilhar igualdade dos espaços de poder e ter respeitados os seus direitos. Nesse contexto, este artigo evidencia que, embora a luta nos últimos quarenta anos tenha contribuído para grandes mudanças, ainda se observa a responsabilidade quase exclusiva das mulheres com as tarefas domésticas. Constata, ainda, sua exclusão na política, quando estudos apontam uma presença de apenas 13\% de mulheres nos legislativos brasileiros, exclusão que também se traduz nos empregos subalternos e baixos salários que demonstram que o capitalismo se articula com o patriarcado no sentido de desvalorizar a força do trabalho feminino, imputando-lhe os cargos menos valorizados e mal remunerados. Conclui que esse fato reflete a divisão sexual do trabalho que criou cisões entre o trabalho produtivo e o reprodutivo, segregando as mulheres nos trabalhos que reforçam as relações de gênero e sua exclusão da vida pública. Palavras-chave: Movimento feminista, patriarcado, ação política, mulheres, relações de gênero.

\section{WOMEN AND FEMINIST MOVEMENT AND ITS ANTI-CAPITALIST ACTION IN BRAZIL AND MARANHÃO}

Abstract:The Feminism action in Brazil which has as mark the seventies, when this movement spread through several Brazilian states, bringing to society the perspective of women, to build a society without gender relations, in which women could share equal spaces of power and have their rights respected. In this context, this article shows that, although the fight over the last forty years has contributed to major changes, it is still observed the almost exclusive responsibility of women with the housework. Shows that, there is still exclusion in politics, when studies indicate a presence of only $13 \%$ of women in Brazilian legislative, exclusion that is also observed in secondary jobs and low wages, which demonstrates that, capitalism articulates with the patriarchate in order to devalue women workforce, imputing undervalued and underpaid positions. This fact reflects the sexual division of labor that created divisions between productive and reproductive work, segregating women in jobs that reinforce gender relations and their exclusion from public life.

Keywords: Feminist movement, patriarchate, political Iction, women, gender relations. 


\section{INTRODUÇÃO}

O feminismo no Brasil tem nuances que reforçam sua diversidade, particularidades e correntes. Sua história está representada a partir das feministas que vivenciaram múltiplas práticas políticas traduzidas em ações e mediações que favoreceram conquistas e impasses. Ao buscar os fios para construir uma memória que dê conta de reconstituir a história do feminismo e dos movimentos de mulheres no Brasil com um olhar mais atento no Estado do Maranhão, faço-o a partir das protagonistas que viveram os acontecimentos de um momento histórico em que cada uma se permitiu e transgrediu naquilo que o feminismo possibilitou, individual e coletivamente, para construir uma história na qual as feministas apontaram novas práticas políticas e novos modos de pensar a sociedade tendo as mulheres como sujeito.

A história das mulheres é uma história construída com silêncios, enfatiza Perrot (2005), porém a história das feministas brasileiras rompe com os silêncios impostos secularmente e torna a luta como um lugar de protestos e de festa. Éramos poucas, sempre fomos! Mas a irreverência nos tornava multidão. Assim foi em vários Estados brasileiros, de São Paulo a Porto Alegre, da Bahia a Pernambuco, do Maranhão ao Acre. Em todos esses estados irradiaram feminismos diversos, ricos em ações que se coletivizaram à medida que as feministas criavam formas alternativas de comunicação, hoje cada vez mais facilitadas pelas redes sociais.

Dos grupos pioneiros que proliferaram nos anos setenta e oitenta, muitas foram as parcerias. Destacamos em especial as estabelecidas entre o Grupo Mulheres da Ilha, em São Luís, e SOSCorpo, de Recife, criados quase simultaneamente. Posteriormente, este movimento chega ao Pará, Ceará, Rio Grande do Norte, Sergipe e se expande a todos os estados do Brasil.

A história dos feminismos no Brasil tem marcos semelhantes, dada a capacidade das mulheres de construir agendas em períodos anteriores às facilidades dos Facebooks de hoje, pois havia naquele momento histórico a necessidade de ampliar os direitos das mulheres ao mesmo tempo em que nos engajamos na luta pela redemocratização do País. A necessidade de articular a luta feminista nasce com o desejo de discutir e se contrapor a um discurso que excluía as mulheres dentro do projeto de democracia que se instaurava no País em finais dos anos setenta e oitenta.

A proposta deste texto é refletir sobre os feminismos no Brasil, analisando sua ação contínua na construção de um modelo de democracia cobrado pelas , contraposição ao modelo conservador, capitalista e patriarcal, capitaneado pelas elites brasileiras que ainda hoje dominam o cenário nacional interferindo de forma direta no governo de
Dilma Rousseff. Neste texto faço uma referência especial ao Maranhão, estado onde se proliferou nos anos oitenta uma intensa movimentação feminista articulada pelos grupos Mulheres da Ilha, Mãe Andresa, Viva Maria e, mais recentemente, o Maria Firmina, além de muitos outros que deram visibilidade às dores e desassossegos das mulheres maranhenses.

$\mathrm{Na}$ discussão deste texto apresentamos em um primeiro momento reflexões sobre o feminismo no Brasil destacando, particularidades deste movimento nos estados do Nordeste, em especial no Maranhão. Na segunda parte do texto refletimos sobre ações anticapitalistas dos feminismos e sobre as questões aglutinadoras de uma luta que tem frutificado em debate e ações e alterando em grande parte a vida das mulheres em diferentes contextos.

2 OS FEMINISMOS NO BRASIL: apontamentos para compreender sua dimensão política

As primeiras organizações de mulheres criadas no Brasil se inserem em movimentos de esquerda que descortinavam as atrocidades cometidas pela ditadura militar e conservadorismos da sociedade brasileira. Oriundas, em grande parte, de partidos clandestinos, estas organizações, profundamente engajadas às causas nacionais e com profundo conhecimento sobre as desigualdades de gênero, exigiam democracia e o fim do regime de exceção no País.

Da ação dessas militantes emergem os primeiros grupos feministas no Brasil, que se localizaram inicialmente em São Paulo, Rio de Janeiro e Bahia no início dos anos setenta. Os acontecimentos do Ano Internacional da Mulher abrem caminhos para refletir sobre as mulheres em variados contextos e ampliar a ação dos grupos pioneiros. Estávamos em 1975 e o mundo percebeu a presença das mulheres e a necessidade de refletir seus problemas a partir delas próprias. Segundo Ferreira, (2011, p. 4):

[...] das pioneiras sufragistas na qual se destaca Bertha Lutz, em São Paulo, Leolinda Dalton na Bahia, Eneida de Moraes no Pará e Violeta Campos, no Maranhão, muitas mulheres no início do Século $X X$ deram um novo sentido à história ao mostrar os acontecimentos a partir de suas vivências, lutas, e que estas vivências traduzem uma forma de retratar os fatos de cada momento do presente.

O que caracterizou e caracteriza a dimensão social e política do movimento feminista é sua capacidade de transgredir, de trazer fatos políticos, de recompor momentos que dão novo sentido à realidade. As ações dos grupos num primeiro momento, como mencionamos, concentraram- 
se no eixo São Paulo, Rio de Janeiro e Bahia. Posteriormente foram irradiando para os Estados do Nordeste, Sul, Norte e Centro-oeste. As dificuldades de expandir as fronteiras desse movimento, dadas as dimensões continentais do País, foram inúmeras. Tais dificuldades, porém, não foram maiores do que o desejo de todas nós, feministas, de socializar ideias e conteúdos que permitiram e possibilitaram a visibilidade de questões até então despercebidas pela sociedade. A ação dos movimentos feministas trouxe a público o universo das mulheres, suas inquietações e bandeiras de luta.

Das inúmeras bandeiras, destacamos a rediscussão sobre o sentido da política, na medida em que incluiu questões consideradas do mundo do privado, que passaram a ser vistas como questões políticas: aborto; violência doméstica e sexual; trabalho igual para salário igual; relações hierárquicas visíveis entre profissionais de profissões semelhantes (veja o caso médico-enfermeira); divisão das tarefas domésticas; parceria na criação dos filhos. O movimento traz para o cenário da política a necessidade da rediscussão sobre o sentido de representação política, uma vez que para nós, mulheres, era, e continua sendo, inadmissível a sub-representação feminina nos espaços de poder legislativo e executivo.

Dessas lutas, nascem as cotas para mulheres na política. Mesmo com sua aprovação, ainda está distante a construção da paridade na vida política, haja vista que no atual contexto somente o Partido dos Trabalhadores aprovou a paridade.

Como podemos observar, o feminismo traz um conjunto de questões que deram a esse movimento visibilidade e respeito. Situação semelhante é percebida em outros países da América Latina e Caribe, Europa e Estados Unidos.

É fato que esse movimento foi capaz de promover uma revolução de ideias reconhecida por vários autores, a exemplo de Hobsbawn (1995), Santos (2001), Castells (1999). São ideias que, como enfatiza Casimiro (1999, p.10), vieram "[...] perturbar a harmonia do saber - social, científico, político - caucionado pelo paradigma científico dominante, androcrático, ajudando a retirar o véu à neutralidade científica." Contribui também para isso a forte presença das pesquisadoras feministas nas academias, que insistem em considerar as mulheres como sujeito e objeto de pesquisa, questionando e transformando a ciência androcêntrica.

\subsection{Os feminismos no Norte e Nordeste}

A ação do feminismo no Norte e Nordeste teve ressonância através de vários grupos, entre os quais o Ação Mulher, que surge em Recife em 1978 "como um grupo de reflexão e autoconsciência" (ARRAZOLA, 2000, p. 79); o Centro da Mulher de João Pessoa, que foi criado em 1979 e, posteriormente, passou a ser denominado Grupo feminista Maria Mulher ao assumir uma identidade feminista propriamente dita." (RABAY, 2000, p. 92). No ano seguinte (1980), nasce em São Luís o Grupo de Mulheres da Ilha, e em 1981 nasce o SOS-Corpo, de Recife.

É importante enfatizar que o Grupo de Mulheres da Ilha nasceu em um momento histórico em que o Maranhão vivia a utopia da união das esquerdas através do movimento Oposição pra Valer.

Enfatiza Ferreira (2011, p. 8).

"É um período marcado pela eclosão de vários movimentos: pela moradia, contra a carestia, contra o racismo, em defesa de Ilha, direitos humanos, nasce ainda neste período o Partido dos Trabalhadores.",

Em Pernambuco, há uma efervescência de grupos criados na década de oitenta: Centro de Mulheres do Cabo, Cais do Parto, Viva Mulher, e os vários núcleos de mulheres ligados à Universidade Rural de Pernambuco, da Federal de Pernambuco e a Fundação Joaquim Nabuco. No Rio Grande do Norte, merece registro a atuação do Grupo Feminista Leila Diniz, que tem atuado de forma mais significativa em meados dos anos noventa, tendo como foco de atuação a questão da violência. Emerge também neste Estado o Grupo de Mulheres pesquisadoras na Universidade Federal do Rio Grande do Norte. Vários desses grupos são co-fundadores, em 1992, da Rede Feminista de Estudos de Gênero no Norte e Nordeste (REDOR), que nasceu

[...] da necessidade das professoras e pesquisadoras do Norte e Nordeste de criar um espaço de discussão regional sobre gênero, a fim de fortalecer os grupos existentes e estimular a criação de novos grupos nas universidades destas duas regiões. (FERREIRA, 2013, p. 20).

A história desses Grupos, e de tantos outros, revela um lado da história das lutas libertárias no Brasil ainda pouco evidenciado nas pesquisas nesse campo. A ausência de estudos que recuperem a dimensão desses grupos e/ou a ação das feministas do norte e nordeste no processo de reconhecimento da identidade e cidadania das brasileiras, nas articulações e implementação de políticas públicas, nos levou a publicar, em 2007, o Livro As Caetanas vão à luta: feminismo e políticas públicas no Maranhão, fruto de estudo desenvolvido no Programa de Pós-Graduação em Políticas Públicas - UFMA, no qual recupero parte de uma história protagonizada por maranhenses, gaúchas, cariocas, paulistas, brancas e negras que possibilitaram ao Grupo de Mulheres da Ilha ser a vanguarda desse movimento em momento histórico no Maranhão. 
A maioria dos estudos reflete um feminismo que ainda não ultrapassou as fronteiras do eixo São Paulo - Rio de Janeiro e dá leves saltos em Minas Gerais, Santa Catarina, Porto Alegre. E os outros feminismos? Por que permaneceram por tanto tempo invisíveis? Por que no presente ainda não conseguem ser protagonistas de uma nova história? (FERREIRA, 2011, p. 9).

No Maranhão, o movimento feminista nasce com o grupo de Mulheres da llha, que se constituiu em julho de 1980 como um espaço de reflexão e aprofundamento das questões levantadas no Curso de Extensão Mulher na Sociedade Brasileira, promovido pela Universidade Federal do Maranhão, ministrado pela Prof ${ }^{a}$ Marisa Corrêa, da UNICAMP. "Às reflexões desse curso se aliaram várias outras mulheres, em busca de espaço em que pudessem se exprimir mais livremente suas ideias." (FERREIRA, 1999, p. 93).

Outros grupos emergiram após a criação do Grupo de Mulheres da Ilha na década de oitenta com diferentes inspirações, dentre eles: o Grupo de Mulheres 8 de Março, Grupo de Mulheres Mãe Andresa, União de Mulheres, Espaço Mulher, Grupo Viva Maria, Mulheres do PDT. Na década de noventa surgem a Pastoral da Mulher, o Grupo Maria Firmina, os Grupos de Estudos nas Universidades, os Departamentos da Mulher nos sindicatos e nos partidos, o Coletivo de Mulheres Trabalhadoras Rurais. (FERREIRA, 2007). Atualmente, estes grupos estão aglutinados no Fórum Maranhense de Mulheres, que articula as lutas no Estado e promove a mediação dos grupos com setores do poder público e outras instituições. A ação desses grupos, segundo a professora Florilena Aranha,

[...] contribui para ampliar o debate, somar esforços em torno de questões comuns e promover a mediação dos grupos com setores do poder público e outras instituições hoje articuladas no Fórum Maranhense de Mulheres, que aglutina os grupos em atividades no Estado. (FERREIRA, 2013).

O feminismo no Maranhão nasce como movimento social, não homogêneo, que questiona a política, o poder, as relações patriarcais e discute teoricamente a mulher como sujeito na sociedade. "O diferencial do feminismo é sua autonomia em relação a partidos, igrejas, e sindicatos que lhe dá um tom, uma diferença metodológica". (BATISTA, 2006).

\section{A AÇÃO ANTICAPITALISTA E ANTIPATRIARCAL DOS MOVIMENTOS FEMINISTAS}

A ação do movimento feminista, tanto na teoria como na prática, se constituiu como um movimento social e político
[...] dado seu potencial profundamente subversivo, desestabilizador, crítico, intempestivo, assim como pela vontade que manifesta de tornar o mundo mais humano, livre e solidário, seguramente não apenas para as mulheres. (RAGO, 2004, p. 36).

Sua ação permanente agregando protagonismos, denúncias e mediação no combate às desigualdades de gênero tornou este movimento protagonista privilegiado em diferentes ações políticas que, se por um lado denunciavam as relações de subalternidade em que viviam as mulheres brasileiras, por outro interferiam para que essas desigualdades fossem combatidas através de um conjunto de propostas encaminhadas em diferentes instâncias: federal, estadual e municipal, e em diferentes espaços - partidário, sindical, refletindo desejos e insatisfações das mulheres que se juntaram em um esforço conjunto para mudar as relações de gênero (FERREIRA, 2011).

Além disso, o movimento feminista articulou diferentes formas de atuação, dentre as quais podemos destacar a formação de redes que possibilitaram enfrentar os desafios desse país cujas distâncias foram sempre desafiantes. A articulação de redes e os diferentes mecanismos de comunicação, impulsionados pelas tecnologias da informação, facilitaram trocas e deslocamentos permanentes para a formação de quadros dentro do movimento em diferentes regiões.

Outras formas de atuação foram se diversificando e imbricando, seja em grupos autônomos ou em organizações não governamentais, nas universidades com a criação dos núcleos de pesquisa de gênero, ou ainda nas parcerias com o Estado através das Secretarias/Coordenadorias da Mulher, dos Conselhos Nacional, Estadual e Municipais da Condição Feminina (FERREIRA, 2007).

Em termos políticos e no processo de luta, os movimentos feministas não desvinculam a questão de classe das questões de gênero nem das questões étnicas raciais, pois estão vinculadas a relações de poder e dominação que perpassam as relações sociais. A multiplicidade de movimentos e suas diversas correntes e linhas de atuação possibilitaram ao feminismo inovar na medida em que se articula com a Marcha Mundial de Mulheres, nas redes de estudos feministas, nos movimentos negros, assim como nas centrais de trabalhadores e partidos políticos.

As polêmicas em torno das ideias do feminismo, que também se dava e se dão intragrupos, ampliavam o debate desconstruindo os estigmas sobre as mulheres baseados em diferenças biológicas que enaltecem qualidades associadas ao sexo feminino como docilidade, sensibilidade, fertilidade, beleza, pureza, rebatidos pelas feministas na medida em que propunham 
romper com a passividade, com o conformismo e a acomodação.

Essas visões ainda não superadas levaram e levam determinadas mulheres a se autodenominarem "[...] femininas e não feministas" sem considerar que esta afirmação implica a negação das bandeiras históricas defendidas pelas mulheres nos últimos quarenta anos. Ser feminista é

\begin{abstract}
"quebrar as barreiras do silêncio imposto pelas estruturas dominantes de gênero e usar permanentemente a voz em defesa dos direitos e no combate às injustiças contra as mulheres (FERREIRA, 2004, p. 2).
\end{abstract}

Compreender o feminismo e se reconhecer como feminista implica compreender a natureza das relações de poder entre homens e mulheres, movida pelo patriarcalismo que mantém as mulheres subjugadas a um modelo que tem o homem como centro das decisões.

O patriarcado, na sua expressão literal, é um sistema de relações em que a propriedade e a posição social se transmitem do pai para o filho varão, em geral o primogênito. No sistema patriarcal, as mulheres são vistas como subordinadas a esse pátrio poder a quem devem obediência. Uma das principais características do patriarcado é sua relação com o androcentrismo, termo que retrata uma visão do homem como centro do mundo e das coisas. Para Costa (2012, p. 30), a perspectiva do patriarcado:

[...] é que seja um instrumento analítico de realidades distintas, culturas diversificadas e processos históricos específicos que atinge as mulheres de formas e graus diferenciados, mas que, no final, todas, independente de como ela se manifesta, vivenciam um sistema de dominação construído a partir de um androcentrismo, vivenciam pelo fato de ser mulheres.

Para Cruz (2013, p.190), embora não haja um entendimento único sobre o conceito de patriarcado, "[...] há um consenso quanto à influência da razão androcêntrica sobre a ciência.", razão por que somente no Século $\mathrm{XX}$ as mulheres passaram a ser consideradas objeto e sujeito de estudos acadêmicos. Foram estes estudos que passaram a desvendar a presença das mulheres em diversas passagens da história e sua contribuição na construção da sociedade.

O patriarcado se filia ao capitalismo mantendo as mesmas regras do poder e excluindo as mulheres dos postos de decisão. Esse modelo perverso contribui para acentuar as desigualdades percebidas pelos indicadores sociais que desnudam a exclusão das mulheres em qualquer circunstância: no trabalho, no sindicato urbano e rural, na política, na igreja.
No que se refere ao trabalho, em recente estudo realizado, analisando 62 profissões, comparando rendimentos de homens e mulheres exercendo ocupações semelhantes,

[...] em apenas um caso, professoras de ensino fundamental com formação em nível médio, a renda do trabalho delas era superior. Ainda assim, a diferença encontrada - de $2 \%$ a mais para elas - fica dentro da margem de erro da pesquisa" (CRUZ, 2012, p. 205).

A opressão das mulheres também se traduz no trabalho rural, quando, segundo dados divulgados por estudiosas da ONU, "[...] a percentagem de mulheres proprietárias de terras e imóveis no mundo não ultrapassa os 3 ou 4\%". (CIRILLA, 2013, p. 3). A lógica da genealogia masculina do poder é, segundo a mesma autora,

"[...] ainda mais evidente para além dos aspectos jurídicos e formais, tem uma dimensão antropológica que dois séculos de lutas pela emancipação ainda não conseguiram superar." (CIRILLA, 2013, p. 3).

Ao refletir sobre a exclusão das mulheres na política, tendo o Brasil como foco, basta observar os dados das últimas eleições para prefeitos e vereadores. Dos 5.565 Municípios, apenas 666 são administrados por mulheres, eleitas na eleição de 2012, representando $11,9 \%$ em relação às eleições de 2008, em que se elegeram 506 prefeitas, representando 9,09\% das mulheres. Para Ferreira (2013, p. 78),

Houve um aumento de $31 \%$ em relação à eleição de 2008. Nesta eleição, porém, foi eleita apenas uma mulher para administrar uma capital: Teresa Surita do PMDB, eleita com 39,26\% dos votos válidos para a Cidade de Boa Vista (Roraima). Em 2008, foram eleitas Luizianne Lins do PT, em Fortaleza (CE), e Micarla de Souza do PV, em Natal (RN). Houve disputas acirradas de mulheres em prefeituras, como a de Manaus, que levou para a disputa do segundo turno a senadora Vanessa Grazziotte do PCdoB, perdendo a eleição para o ex-senador Artur Virgílio Neto (PSDB), forte adversário do Partido dos Trabalhadores.

Estes dados se tornam mais expressivos quando comparados às eleições de 1972, quando foram eleitas apenas 60 mulheres para as prefeituras municipais. Podemos afirmar, então, que nos últimos quarenta anos não houve aumento acentuado, já que as mulheres representam apenas $11 \%$ das prefeitas eleitas e 13,3\% das vereadoras. (FERREIRA, 2013). 
Em se tratando da igreja, são emblemáticos os embates das feministas com os fundamentalistas religiosos, responsáveis pelo retrocesso dos avanços propagados pela igreja católica nos anos setenta. Os fundamentalistas têm sido responsáveis pelo silêncio da sociedade sobre questões como aborto, corpo, sexualidade. A ação dos fundamentalistas tem favorecido um movimento conservador que interfere de forma direta na ação do Estado, especialmente no Congresso Nacional, palco de muitas disputas entre deputados progressistas e conservadores.

Ao analisar o capitalismo, Marx (1988) o considerou como um modo antagônico de desenvolvimento histórico, em que as relações de antagonismos ocorrem em todas as épocas históricas e aparecem em todos os modos de produção. É o que temos observado no atual contexto, com as pressões que os grupos hegemônicos detentores do capital e de poder fazem ao governo de Dilma Rousseff para que não se efetivem as reformas propostas por ela. O exemplo mais evidente é o tratamento dado pelo governo à Reforma Agrária, que foi uma das políticas que pouco se alterou nos governos de Lula e Dilma Rousseff.

A desigualdade de classe é considerada por Karl Marx como a geradora de todas as outras desigualdades, porque está relacionada ao capital (dinheiro) financeiro. É vista desta forma porque os detentores de capital são, também, os donos das propriedades e dos meios de produção, são os donos das terras, das plantações de sojas, das fazendas de gado, das fábricas, das indústrias, dos meios de comunicação. São eles que detêm o poder e determinam as formas de socialização. Ao acumular e deter os meios de produção, a classe dominante acumula a maior parte dos bens geradores de capital e, assim, promove a desigualdade social. A desigualdade é, em grande parte, gerada pela concentração de poder e dinheiro nas mãos dos capitalistas, em sua maioria homens brancos.

\subsection{A divisão sexual do trabalho e a exclusão das mulheres}

A exploração das mulheres pelo sistema capitalista é visível a partir do conceito de divisão sexual do trabalho, visto por Matthaei (2012) como "[...] a atribuição de atividades sociais diferentes e desiguais segundo o sexo". Este é considerado um conceito chave para entender como se constroem as diferenças de gênero a partir dos papéis sexuais que determinam atividades de homem e de mulher, e contribui para a exclusão das mulheres do mundo público e sua segregação ao espaço doméstico.

$\mathrm{Na}$ visão de Kergoat (2009, p. 67) a divisão sexual do trabalho:

\footnotetext{
[...] é decorrente das relações sociais de sexo; esta forma é adaptada historicamente a cada sociedade. Ela tem por características a destinação
}

prioritária dos homens à esfera produtiva e das mulheres à esfera reprodutiva e, simultaneamente, a apreensão pelos homens das funções de forte valor social agregado (políticas, religiosas, militares, etc [...]

A divisão sexual do trabalho criou cisões entre o trabalho produtivo e o reprodutivo, ao mesmo tempo em que excluiu as mulheres da vida pública. Para Nalu Faria, divisão social do trabalho tem dois princípios organizadores:

[...] o princípio de separação (existem trabalhos de homens e trabalhos de mulheres) e o princípio de hierarquização (um trabalho de homem "vale" mais do que um trabalho de mulher). Eles são válidos para todas as sociedades conhecidas, no tempo e no espaço. (FARIA, 2008).

E, acrescentamos, contribuem em grande parte para reforçar a subalternidade das mulheres e seu aprisionamento às tarefas domésticas.

A segregação das mulheres no mundo privado e na labuta diária do lavar, passar, cozinhar, cuidar dos filhos contribui para ampliar sua exclusão e reforça mais ainda a divisão sexual do trabalho, que, na visão de Duque-Arrazola (2012, p. 254):
[...] se materializa, segundo os procedimentos de classe e raciais de mulheres e homens e são determinantes do modo e lugar de sua inserção no mercado de trabalho... Não é por acaso que as mulheres inserem-se majoritariamente nos postos e ocupações em que prevalecem os trabalhos manuais, o atendimento e o uso reduzido de tecnologias, caracterizadas como demandantes das "qualidades femininas"; diferentes daquelas ocupadas pelos homens a quem se exige força, resistência, e supostamente maiores conhecimentos.

Esses fatos contribuem para que as mulheres ainda sejam pouco percebidas nas carreiras do campo das tecnologias e tenham salários inferiores aos homens. Na visão de Cruz (2012, p. 196), tal fato é marca das sociedades capitalistas, e se constitui uma das temáticas em que a hierarquia de gênero mais fortemente se expressa. Para a autora:

Os trabalhos realizados pelos homens rendem mais (em dinheiro), são mais valorizados pela sociedade (prestígio), são restritos à jornada de trabalho remunerada, entre outros aspectos da supremacia do trabalho masculino inserido no mercado de trabalho. O trabalho feminino, que se concentra claramente na "produção e reprodução" de seres humanos, vale menos. 
A conexão entre capital e masculinidade branca fornece, segundo Matthaei (2012), importantes insights para compreender seu funcionamento e seu distanciamento dos princípios que regem as relações de trabalho pensado como uma atividade humana importante e necessária para satisfazer as necessidades de homens e mulheres. A mesma autora reforça, ainda, a visão de teóricos/as raciais que comparam o mesmo processo de exploração do capital nas populações negras, mostrando como as divisões raciais do trabalho produziram e reproduziram raças, da mesma forma como a divisão sexual do trabalho reproduz as relações de gênero.

As relações de gênero, assim como as relações de classe, são construídas historicamente a partir das hierarquias que transformam as diferenças em desigualdades, tanto sociais quanto políticas, na medida em que materializa a opressão das mulheres. Para Arazzola (2012), Ferreira (2013), Cruz (2012), Costa (2012), as relações de gênero nos permitem compreender com mais profundidade suas imbricações com o capitalismo e suas diferentes formas de opressão das mulheres.

Esses fatos levaram várias estudiosas, a exemplo da filósofa Sandra Harding e da economista Julie Matthaei, (2003; 2012) a enfatizar a necessidade das feministas em assumir posturas mais radicais marxistas e, ao mesmo tempo, antirracistas como estratégia de combater o capitalismo, uma vez que esse modelo econômico notadamente racista e patriarcal adotou ao longo de toda a sua ascensão o exercício contínuo de uma cultura baseada na competição, no desprezo aos negros, às mulheres e aos pobres.

O capitalismo se firma a partir do fortalecimento das linhagens familiares patriarcais, proprietárias e brancas. Com o capitalismo instaurado na Europa, observou-se um sistema de mercantilização que foi ao longo do tempo se universalizando, se sedimentando e ampliando a partir da produção de mais valia. "É um sistema que mercantiliza as relações, as pessoas e as coisas, transformando as pessoas em mercadorias." (IANNI, 1988, p. 9).

Assim, a luta do feminismo hoje subentende a luta contra o patriarcado, contra o racismo e a luta contra o capitalismo. Para adotar uma perspectiva feminista anticapitalista e antipatriarcal, é importante reconstruir a história das mulheres, a fim de compreender como foram construídos os modelos que as subordinaram ao jugo patriarcal, e, ao mesmo tempo, "[...] compreender a importância econômica da família, que é negligenciada pela análise materialista tradicional.", enfatiza Matthaei (2012). A partir dessa compreensão é que a sociedade poderá entender a dimensão e importância do trabalho doméstico enquanto trabalho não remunerado que contribui para:
[...] assegurar a reprodução diária de todos os membros da sociedade; mais ainda, sua organização em famílias nucleares isoladas no capitalismo reproduz a fragmentação da comunidade, tão danosa ao tecido social. A junção de rendas para um fim comum e a transmissão de bens de geração a geração de uma família reproduzem a classe, assim como a desigualdade racial/étnica. As práticas parentais - em particular, a autoritária - preparam as crianças para a participação em nossas instituições políticas e econômicas nãodemocráticas. (MATTHEI, 2002, p.62).

Assim, o capitalismo reproduz os seus modelos de dominação incutindo nas crianças e jovens desde muito cedo valores consumistas, racistas, patriarcais, que contribuem para a manutenção do status quo da sociedade que se mantém praticamente fiel a princípios que reza o capital.

Para as feministas, esta luta ainda não está ganha. É preciso maior pressão social, é preciso articular forças com outros movimentos para que se possa vislumbrar em um futuro próximo uma sociedade de iguais.

\section{CONCLUSÃO}

A luta contra o capitalismo e contra o racismo é também a luta dos feminismos, pois se insere no reconhecimento da dignidade das mulheres à medida que traz à tona as duplas jornadas, a exploração dos menores salários, a violência doméstica, a falta de tempo para participar das instâncias partidárias e, consequentemente, da vida pública. Também traz para o debate a necessidade de intensificar a luta pela descriminalização do aborto, na qual está explícita a luta pelo direito ao corpo, a que os fundamentalistas posicionam-se contra. Eles querem desapropriar as mulheres do poder de decidir sobre o que querem e podem fazer com suas vidas.

Nas manifestações ocorridas em junho e julho próximo ${ }^{1}$, as feministas se juntaram aos milhares de jovens trazendo essas bandeiras, tendo a luta pelo direito ao corpo como luta central, uma vez que nesta luta está implícito um enfrentamento profundo aos fundamentalismos religiosos que hoje se opõem aos avanços dos direitos das mulheres. Para Freire (2013), não se trata apenas de um embate individual, da mulher que se vê diante de escolhas em relação à gravidez e à sexualidade. Trata-se da discussão sobre a apropriação do corpo feminino como "[...] fundamento da igreja que sacraliza a maternidade como uma condição que submete a mulher e não como uma escolha que a empodera." (FREIRE, 2013, p.2). Além disso, o Estado desapropria as mulheres do seu 
corpo, criminalizando suas ações e decisões ao sonegar direitos que a mulher tem sobre ele. $O$ corpo feminino é apropriado pelo capital e pela mídia, que o mercantilizam, e ao mesmo tempo "[...] pela sociedade, que discrimina comportamentos, impõe padrões e papéis e admite o seu controle pela violência social e doméstica." (FREIRE, 2013, p.2). A descriminalização do aborto é, portanto, uma medida que dará às mulheres autonomia para decidir sobre o melhor para suas vidas sem interferências.

Assim, ao encerrar este breve texto, afirmamos que o modelo capitalista tem contribuído para acirrar este debate, ao mesmo tempo em que reforça a divisão sexual do trabalho, o racismo e a exclusão das mulheres. É necessário, portanto, que as feministas articulem novas estratégias de oposição e resistência ao atual modelo que tanto tem penalizado as mulheres.

\section{REFERÊNCIAS}

ARANHA, Florilena. Entrevista sobre a ação do movimento feminista no Maranhão. São Luís, 2013.

BATISTA, leda Cutrim. Quando o passado ilumina o presente. In: FERREIRA, Maria Mary; ALVARES, Luzia; SANTOS, Eunice Ferreira. (Orgs.). Os poderes e os saberes das mulheres: a construção do Gênero. São Luís: EDUFMA, 2001. p. 41-54.

CASIMIRO, Isabel Maria Alçada Padez Cortesão. Paz na terra, guerra em casa: feminismo e organizações de mulheres em Moçambique. 1999. 304 Dissertação (Mestrado) - Faculdade de Economia. Coimbra, Universidade de Coimbra, 1999.

CASTELLS, Manuel. 0 poder da identidade. São Paulo: Paz e Terra, 1999. v.2.

COSTA, Ana Alice Alcântara. Reflexões acerca do poder, patriarcado e da cidadania das mulheres. In: FERREIRA, Maria Mary. (Org.). Gênero, política e poder: participação das mulheres nos espaços de poder no Norte Nordeste. São Luís: EDUFMA, 2012. p. 15-44.

CRUZ, Maria Helena Santana. Trabalho e condições de vida de mulheres na realidade brasileira. In: FERREIRA, Maria Mary (Org.). Conhecimento feminista e Relações de gênero no Norte e Nordeste brasileiro. São Luís: REDOR; NIEPEM, 2012. p. 189-211.

DUQUE-ARRAZOLA, Laura Suzana. Mulheres e feminismos em Pernambuco: reflexões sobre uma trajetória. In: SALES, Celecina de Maria Veras; AMARAL, Célia Chaves Gurgel do; ESMERALDO, Gema Galgani. Feminismo: memória e história. Fortaleza: Imprensa Universitária, 2000. p. 77-88.
Qualificação profissional e força de trabalho feminina no capitalismo contemporâneo. In: FERREIRA, Maria Mary (Org.). Conhecimento feminista e Relações de gênero no Norte e Nordeste brasileiro. São Luís: REDOR; NIEPEM, 2012. p.251-264.

FARIA, Nalu. A crise e as desigualdades de gênero. Le Monde Diplomatique Brasil, Paris, 2013. Disponível em:<http://www.diplomatique.org.br/ artigo.php?id=480>. Acesso em: 15 jul. 2013.

FERREIRA, Maria Mary. Nos bastidores da Tribuna: mulher política e poder no Maranhão. São Luís: EDFMA, 2010.

FREIRE, Rita. As feministas e o sentido das marchas no Brasil. A Ciranda, [S. I.], 2013. Disponível em: <http://www.ciranda.net/article7121.html>. Acesso em: 16 jul. 2013.

HOBSBAWN, Eric. A era dos extremos: o breve século XX 1914-1991. 2. ed. São Paulo: Companhia das Letras, 1995.

IANNI, Otavio. Introdução A produção da sociedade capitalista. In Marx: sociologia. 6. ed. São Paulo: Ática, 1988. p. 7-42.

KERGOAT, Daniele. Divisão sexual de trabalho e relações sociais de sexo. In: HIRATA, Helena, et al. (Orgs.). Dicionário crítico feminista. São Paulo: UNESP, 2009. p.67-75.

MATTHAEI, Julie. Por que os/as economistas feministas/marxistas/anti-racistas devem ser economistas-feministas-marxistas-antiracistas? In: FARIA, Nalu; NOBRE, Mirian. Economia feminista. São Paulo: SOF, 2002, p. 4471.

RABAY, Glória de Lourdes Freire. Movimentos de mulheres na Paraíba: conquistas e desafios. In: SALES, Celecina de Maria Veras; AMARAL, Célia Chaves Gurgel do; ESMERALDO, Gema Galgani. Feminismo: memória e história. Fortaleza: Imprensa Universitária, 2000. p. 89-96.

RAGO, Margareth. Feminismo e subjetividade em tempos pós-modernos. In: COSTA, Cláudia de Lima; SCHMIDT, Simone Pereira. (Org.). Poéticas e políticas feministas. Ilha de Santa Catarina: Mulheres, 2004.

SANTOS, Boaventura de Sousa. A crítica da razão indolente: contra o desperdício da experiência - para um novo senso comum, a ciência, o direito e a política na transição paradigmática. 3. ed. São Paulo: Cortez, 2001. 
SCAVONE, Lucila. Dar a vida e cuidar da vida: feminismo e Ciências Sociais. São Paulo: UNESP, 2004.

NOTA

1 Estou me referindo às manifestações ocorridas em todo o Brasil, no período que compreende junho e julho de 2013, e que-se estendeu até meados de setembro em alguns estados brasileiros.

\section{Mary Ferreira}

Bibliotecária

Doutora em Sociologia pela Universidade Estadual

Paulista (UEP)

Professora da Universidade Federal do Maranhão (UFMA)

E-mail: mmulher13@hotmail.com

Universidade Federal do Maranhão - UFMA

Cidade Universitária do Bacanga

Avenida dos Portugueses, 1966-Bacanga

65080-580- São Luís-Ma 